JASEM ISSN 1119-8362

All rights reserved
Full-text Available Online at www.bioline.org.br/ja

\title{
Effect of Formalin on the Hatching Rate of eggs and Survival of larvae of the African Catish (Clarias gariepinus)
}

\author{
${ }^{* 1}$ AKPOILIH, B U; ${ }^{2}$ ADEBAYO, O T \\ ${ }^{1}$ Department of Biological Sciences, Novena University, Ogume, Delta State, Nigeria \\ ${ }^{2}$ Department of Fisheries and Aquaculture, Federal University of Technology, Akure, Nigeria \\ Correspondence author: Akpoilih, .B.U \\ Email: uzeziu2@yahoo.co.uk,Tel: +2348134381645
}

\begin{abstract}
The effect of formalin on the hatching rate of eggs of the African catfish and subsequent survival of the larvae were investigated using range finding and definitive tests to determine the impact of formalin for 15 minutes. In the range finding test, $0 \mathrm{mgl}^{-1}$ (control), $250 \mathrm{mgl}^{-1}, 500 \mathrm{mgl}^{-1}, 750 \mathrm{mgl}^{-1}$, and $1000 \mathrm{mgl}^{-1}$ of formalin were used to define the threshold limit of tolerance of eggs to formalin. There were significant differences in the hatching rate and survival of early larvae between the control and all four formalin concentrations $(\mathrm{p}<0.05) .500 \mathrm{mgl}^{-1}, 750 \mathrm{mgl}^{-}$ ${ }^{1}$, and $1000 \mathrm{mgl}^{-1}$ of formalin resulted in total egg mortality ( $0 \%$ hatching rate). In the definitive test, the difference between the control and $50 \mathrm{mgl}^{-1}, 100 \mathrm{mgl}^{-1}, 150 \mathrm{mgl}^{-1}$, and $250 \mathrm{mgl}^{-1}$ of formalin was significant in hatching rate $(\mathrm{p}<0.05)$. There was no significant difference between $50 \mathrm{mgl}^{-1}, 100 \mathrm{mgl}^{-1}, 150 \mathrm{mgl}^{-1}(\mathrm{p}>0.05)$. The survival rate of early larvae of Clarias gariepinus showed no significant difference between the control and $50 \mathrm{mgl}^{-1}, 100 \mathrm{mgl}^{-1}, 150 \mathrm{mgl}^{-1}$, and $250 \mathrm{mgl}^{-1}(\mathrm{p}<0.05)$.In conclusion, formalin, although applied as a broad spectrum chemical in aquaculture in the treatment of fish disease, particularly fungi, as in this study, where it effectively reduced fungi on eggs and larvae of Clarias gariepinus, impacted negatively in terms of acute toxicity effect on the fish. Its use should be carefully investigated to reduce potential toxic effect on fish. @JASEM
\end{abstract}

Aquatic fungi (Saprolegniales) are ubiquitous in natural water supplies of fish hatcheries often causing serious disease problem. Malachite green is effective in control of fungus on fish and fish eggs, but due to suspected teratogenicity, that is potential carcinogenicity (Meyer and Jorgenson 1984, Fitzpatrick et al, 1995) and / or mutagenic properties (Marking et al, 1994), its use was limited to the treatment of non-food fish (that is egg or adult salmon held for spawning).

Presently, there is one registered aquatic fungicideformalin. Formalin is a solution of $37-40 \%$ formal dehyde gas dissolved in water (Van waters and Rogers, 1988; Schnick, 1973). It is effective in treating fungi, external parasites, including protozoans and monogenic trematodes and widely used in therapeutic and prophylactic treatment by aquaculturists (Floyd, 1996). It is one of the most effective anti fungal agents used to control fungal infections on eggs and improves hatching rate. Formalin effectively kills parasites on gills, skin and fins. In addition, high concentrations of formalin are used to control fungi on fish eggs. It is not effective against internal infections of any type.Formalin is applied as a bath treatment. It can be applied as a prolonged bath, which means it is placed into the water indefinitely, or it can be applied as a short-term bath, which means fish are placed into the bath for a relatively short period of time (30 to 60 minutes) and then placed into clean (untreated) water. The concentration of chemical used is determined by the period of time the fish are to be in contact with the chemical, the temperature of the water, and the condition of the fish.

Email: uzeziu2@yahoo.co.uk,Tel: +2348134381645
Clariid catfishes constitute a major family of food fish of economic value in sub- Saharan Africa. The important genera in this family, Heterobranchus and Clarias are widely used in Africa aquaculture.These are prominent in African aquaculture due to their fast growth rate, resistance to diseases, tolerance to high density culture, ability to grow on a wide range of natural and low cost artificial foods and ability to withstand low oxygen and $\mathrm{pH}$ levels (Zheng et al, 1988;Fagbenro et al, 1993). The effects of formalin, using range and definitive tests were investigated with the aim of determining the effectiveness of the chemical in reducing fungal infection on eggs, particularly, Saprolegnia (which causes egg mortality and reduces hatching of fertilized, viable fish eggs, causing huge loss to aquaculture industry worldwide) and consequently, hatching and survival of larvae .

\section{MATERIALS AND METHODS}

Procurement and Conditioning of the Brooders (Matured fish): Four pairs of the gravid Clarias gariepinus fish, with mean weight between $200 \mathrm{~g}$ and $500 \mathrm{~g}$ were procured from a reliable source at Fanibi junction, Ondo road, Akure, Ondo State. They were then acclimatized without food for 36 hours in four glass tanks $\left(75 \times 40 \times 40 \mathrm{~cm}^{3}\right)$ in the fisheries and wildlife laboratory, Federal University of Technology, Akure, Ondo State at a density of 2 fish per tank.Each tank with 90 litre capacity was filled with 40 litres of clean water at temperature between $23^{0}-25^{\circ} \mathrm{C}$. The acclimation of the brooders was done for adaptation to test laboratory condition such as light, duration of light and dark period and ambient temperature, which are critical to maturation and spawning of eggs in captivity.About 24 hours after being stocked in the tanks , 2 females were collected 
prior to injection for the range finding test, preceding the definitive test.

Breeding Procedure: The breeding procedure started with the collection of pituitary gland, which stimulate spawning. The pituitary was obtained by using a pair of tweezers after dissecting the head where it is located. After collection, It was put in a mortal containing $1 \mathrm{ml}$ of a physiological salt solution , which was prepared by dissolving $9 \mathrm{~g}$ of common salt in 1 litre of filtered water.The pituitary was grinded immediately and drawn into a $6 \mathrm{ml}$ hypodermic syringe with the suspension of the freshly collected pituitary injected intramuscularly into a second female fish, with the injection time between 17:0018:00 hours in the evening, while the latency period (the time between injection and stripping of the fertilized eggs) was between 11-14 hours.A pair of gravid(ripe) males were seined out of the holding tank for milt (sperm, in man) collection for fertilization of the eggs. The milt was obtained by dissecting the testes, which milt was squeezed out evenly on the eggs mass of the injected female collected after latency period elapsed and mixed with clean water added to suspend the milt ,after fertilization.

Range Finding Test: After fertilization, 150 eggs were put in each of the five concentrations, replicated thrice, of formalin $\left(0 \mathrm{mg}^{-1}, 250 \mathrm{mgl}^{-1}, 500 \mathrm{mgl}^{-1}, 750\right.$ $\mathrm{mgl}^{-1}$, and $1000 \mathrm{mgl}^{-1}$ ) for 15 minutes exposure time to determine the effective concentration that could reduce Saprolegnia growth(resulting from dead and unfertilized eggs and stickiness of the eggs), threshold concentration for formalin on the eggs as well as the hatching and survival of larvae. The eggs were removed after 15 minutes and placed in five (15 litre) transparent plastics, replicated thrice, for each concentration of formalin, with each replicate receiving the treated 150 eggs. The fifteen plastics, each filled with 3 litres of water, were aerated two days before fertilization to enable the eggs utilize dissolved oxygen for fertilization and survival of the hatched larvae.

Definitive Test: The same breeding procedure was carried out for the definitive test with the fertilized eggs collected from the other set of female gravid, which were fertilized with the milt of the remaining male pair. The eggs were also subjected to similar treatment procedures as in the range finding test, but with five different concentrations: $0 \mathrm{mg}^{-1}$ (control), $50 \mathrm{mgl}^{-1}, 100 \mathrm{mgl}^{-1}, 150 \mathrm{mgl}^{-1}$, and $250 \mathrm{mgl}^{-1}$ of formalin.
Determination of Hatching Rate: This was successfully carried out by counting the total number of hatched eggs in each replicate and expressing it as a percentage of the total number of eggs. This can be mathematically expressed as: \% hatching rate =Number of hatched eggs /Total number of eggsx 100 .

Determination of survival rate: Percentage survival was determined by counting the total number of survived larvae after formalin treatment after one week and expressing such as a percentage of the total hatched larvae in each replicate tank. Mathematically, it is expressed as: \% survival $=$ Number of survived larvae/Total number of hatched larvaex 100 .

\section{RESULTS AND DISCUSSION}

The result of the range finding test showed that hatching rate was between $65 \%$ and $69 \%$ with mean hatching rate of $65.3 \pm 3.51 \%$ in the control, which was significantly different from $250 \mathrm{mg}^{-1}$ concentration of formalin-treated eggs $(\mathrm{p}<0.05)$, which ranged between $3 \%-4 \%$ with a mean hatching rate of $3.67 \pm 0.58 \%$. No hatching was noted in the concentration of $500 \mathrm{mgl}^{-1}, 750 \mathrm{mgl}^{-1}$, and $1000 \mathrm{mgl}^{-}$ ${ }^{1}$.The result is shown in table 1 below. T he definitive test result showed that there was also a significant difference between the control and $50 \mathrm{mg}^{-1}$ concentration of formalin $(p<0.05)$. This showed that formalin has effect on hatching of African catfish decreasing it with increasing concentration from 50 $\mathrm{mgl}^{-1}$ to $250 \mathrm{mgl}^{-1}$.

Although survival rate followed the same trend as the hatching rate, decreasing with increasing concentration from $50 \mathrm{mgl}^{-1}$ to $250 \mathrm{mgl}^{-1}$, there was , however, no significant difference in the survival rate between control and $50 \mathrm{mgl}^{-1}, 100 \mathrm{mgl}^{-1}, 150 \mathrm{mgl}^{-1}$, and $250 \mathrm{mgl}^{-1}(\mathrm{p}<0.05)$. This is presented in table 2 below. Water quality parameters measured during the experiment showed temperature was $24.5^{\circ} \mathrm{C}$, dissolved oxygen was between $3.45 \mathrm{mg}^{-1}-4.55 \mathrm{mg}^{-1}$, while $\mathrm{pH}$ values ranged between 7.87 and 8.01 with all parameters within the optimum tolerable range for larvae as shown in Table 3. It was noticed from the study that high formalin concentration was toxic to eggs of African catfish, underlying three hazardous properties of a chemical as potential toxicity, persistence and bioaccumulation (Svobodova, 1993).It clearly shows formalin has the potential of being toxic, if higher concentrations are used. Floyd (1996) reported that formalin toxicity increase when temperature is above $21^{\circ} \mathrm{C}\left(70^{0} \mathrm{~F}\right)$. 
Table 1.. Water quality parameters of the test medium. Data are means \pm S.E $(n=3$ replicate per treatment $)$

\begin{tabular}{llllll}
\hline Parameter & $0 \mathrm{mgl}^{-1}$ (control) & $50 \mathrm{mgl}^{-1}$ & $100 \mathrm{mgl}^{-1}$ & $150 \mathrm{mgl}^{-1}$ & $250 \mathrm{mgl}^{-1}$ \\
\cline { 1 - 4 }$\left({ }^{0} \mathrm{C}\right)$ & $24.50 \pm 0.00$ & $24.50 \pm 0.00$ & $24.50 \pm 0.00$ & $24.50 \pm 0.00$ & $24.50 \pm 0.00$ \\
$\mathrm{pH}$ & $7.97 \pm 0.03$ & $7.90 \pm 0.02$ & $7.92 \pm 10.06$ & $7.94 \pm 0.06$ & $7.98 \pm 0.02$ \\
$\mathrm{DO}_{2}\left(\mathrm{mg}^{-1}\right)$ & $4.44 \pm 0.13$ & $3.97 \pm 0.26$ & $3.74 \pm 0.16$ & $3.60 \pm 0.18$ & $3.50 \pm 0.17$ \\
\hline
\end{tabular}

Data are means \pm S.E ( $n=3$ replicate per treatment) expressed as \% of total number of eggs for hatchability and total hatched larvae for survival. Letters with the same superscript in the same row are not significant $(p>0.05)$.

Table 2. Definitive test of formalin on Clarias gariepinus and survival of early fry

\begin{tabular}{llllll}
\hline Treatments & $\begin{array}{l}0 \mathrm{mgl}^{-} \\
{ }^{1} \text { (control) }\end{array}$ & $50 \mathrm{mgl}^{-1}$ & $100 \mathrm{mgl}^{-1}$ & $150 \mathrm{mgl}^{-1}$ & $250 \mathrm{mgl}^{-1}$ \\
\hline$\%$ Hatchability & $61.3 \pm 5.03^{\mathrm{a}}$ & $33.3 \pm 14.05^{\mathrm{b}}$ & $24.00 \pm 9.17^{\mathrm{bc}}$ & $19.3 \pm 4.61^{\mathrm{bd}}$ & $7.30 \pm 2.31^{\mathrm{e}}$ \\
$\%$ Survival & $95.7 \pm 1.57^{\mathrm{a}}$ & $85.53 \pm 9.56^{\mathrm{a}}$ & $84.77 \pm 10.96^{\mathrm{a}}$ & $80.07 \pm 6.67^{\mathrm{a}}$ & $75.57 \pm 21.41^{\mathrm{a}}$
\end{tabular}

Data are means \pm S.E ( $n=3$ replicate per treatment) expressed as $\%$ of total number of eggs for hatchability and total hatched larvae for survival. Letters with the same superscript in the same row are not significant $(p>0.05)$.

Table 3. Range finding test and toxicity effects of formalin on Clarias gariepinus and survival of early fry

\begin{tabular}{llllll}
\hline Treatments & $\begin{array}{l}0 \quad \mathrm{mg} / \mathrm{l} \\
(\text { control) }\end{array}$ & $250 \mathrm{mgl}^{-1}$ & $500 \mathrm{mgl}^{-1}$ & $750 \mathrm{mgl}^{-1}$ & $1000 \mathrm{mgl}^{-1}$ \\
\hline$\%$ & $65.3 \pm 3.51^{\mathrm{a}}$ & $3.67 \pm 0.58^{\mathrm{b}}$ & $0.00 \pm 0.00$ & $0.00 \pm 0.00$ & $0.00 \pm 0.00$ \\
$\begin{array}{l}\text { Hatchability } \\
\% \text { Survival }\end{array}$ & $94.4 \pm 2.19^{\mathrm{a}}$ & $52.8 \pm 0.94^{\mathrm{b}}$ & $0.00 \pm 0.00$ & $0.00 \pm 0.00$ & $0.00 \pm 0.00$ \\
\hline
\end{tabular}

But in this study, the maximum temperature recorded was $25^{\circ} \mathrm{C}$, which might have caused total egg mortality, acting synergistically with high formalin concentration. It was also noted that high concentration of the chemical delayed hatching, caused total egg mortally in treatment with a very dose of the chemical. Although, fungal infections are difficult to treat and prevent, having a wide range of temperature tolerance from $3^{0} \mathrm{C}$ to $33^{0} \mathrm{C}$, reflecting the thermal preferences of host (Pickering and Willoughby, 1982), formalin use in small concentration effectively reduced fungal infection in the eggs and fry of Clarias gariepinus ,but impacted negatively on hatchability of the eggs. Formalin is effective in treating saprolegnia (Fitzpatrick et .al., 1995; Mitchell and Collins, 1997), and is the only fungicide registered for use in aquaculture in the US (Bruno and Woods, 1994). Bailey (1984) and Bailley and Jeffry (1989) reported the results of tests with over 200 compounds that were chosen for fungicidal activity with formalin showing potential for control of fungus on fish eggs. In the trial , $1667 \mathrm{mg}^{-1}$ concentration of formalin was considerably more effective than $250 \mathrm{mg}^{-1}$ for decreasing infection rate ($3.6 \%)$ and improving the hatching rate $(87 \%$ vs $57 \%)$ in rainbow trout, a temperate fish, at $12^{\circ} \mathrm{C}$. In fact, the high treatment of formalin produced a better hatch rate than any of the candidate antifungal agents, although, the effective concentration that can be used depend on the time of application, type of fish and kind of parasite targeted (Herwig, 1979). All these factors might have influenced the behavior of formalin used in this study.
Acknowledgements: I wish to show my s gratitude to my untiring and hard working mentor and supervisor Dr. O.T. Adebayo, Department of fisheries and aquaculture, Federal University of Technology, Akure for finding time to edit this work and for his show of benevolence in form of financial commitment to this research. Special thanks goes to Prof. O.A Fagbenro, Department of fisheries and aquaculture, Federal University of Technology, Akure, for his fatherly advice and commitment to academic excellence. You taught me how to commit myself to challenges in a changing world.

\section{REFERENCES}

Bailey, T.A (1984). Aspect of the biology of catfish. Clarias lazera (C and V) related to its economic cultivation. Hydrobiologia. 110:296-303.

Bialey,T.A;Jeffry,S.M (1989).Evaluation of 200 candidate fungicides for use in fish culture.US Fish and Wildlife Service investigation in fish control. 99Pp.

Fagbenro, O.A,;Adedire,C.O;Owoseni, E.A and Ayotunde, E.O. (1993)Studies on the biology and aquaculture potential of feral catfish, Heterobranchus bidorsalis ( Geoffry St Hillaaire 1904). Claridae in tropical zoology.

Fitzpatrick, M.S; Screck, C.B; C hitwood, R.L (1995). Evaluation of three candidate fungicides 
for treatment of adult spring chinock salmon. Progress Fish Cul. 57:153-155

Floyd, R.F (1996).Use of formalin in parasite. Cooperative extension service, Institute of food and Agricultural Sciences, Unioversity of Florida, Gainsville, 32611

Herwig (1979). The hand book of drugs and chemicals used in the treatment of fish diseases. A manual of fish pharmacology and material.

Marking, L.T; Rack, J.J; Schreier, T.M (1994). Evaluation of antifungal agent for culture..Progress Fish cl.56(4):225-231.
Mitchell, A.J;Collins, C.B (1997)Review of the therapeutic uses of hydrogen peroxide in fish production .Aquacul. Mag. 23(3):74-79.

Pickering, A.D;Willoughby, C.G (1982). In: microbial diseases of fish .Edited by R.J Roberts. Academic press, London, England.Pp. 271-287.

Schnick, A (1973). Formalin as a therapeutant in fish culture. US Department of Interior Fish and Wildlife Service, Wasshington D.C.p1-72

Van Waters ;Rogers, Inc. (1998). Material Safety Data Sheet. Van Waters and Rogers, Inc. Seattle, W.A

Zheng Wembians, Pan Jionghus;Liu Wensheg (1980). Review .Culture of catfish in china .Aquaculture 75:35-44 